\title{
Seismological evidence for thermo-chemical heterogeneity in Earth's continental mantle
}

\author{
Federico D. Munch ${ }^{1, *}$, Amir Khan ${ }^{2,1}$, Benoit Tauzin ${ }^{3,4}$, Martin van Driel $^{1}$, \\ Domenico Giardini ${ }^{1}$
}

\begin{abstract}
Earth's thermo-chemical structure exerts a fundamental control on mantle convection, plate tectonics, and surface volcanism. There are indications that mantle convection occurs as an intermittent-stage process between layered and whole mantle convection in interaction with a compositional stratification at $660 \mathrm{~km}$ depth. However, the presence and possible role of any compositional layering in the mantle remains to be ascertained and understood. By interfacing inversion of a novel global seismic data set with petrologic phase equilibrium calculations, we show that a compositional boundary is not required to explain shortand long-period seismic data sensitive to the upper mantle and transition zone beneath stable continental regions; yet, radial enrichment in basaltic material reproduces part of the complexity present in the data recorded near subduction zones and volcanically active regions. Our findings further indicate that: 1) cratonic regions are characterized by low mantle potential temperatures and significant lateral variability in mantle composition; and 2) chemical equilibration seems more difficult to achieve beneath stable cratonic regions. These findings suggest that the lithologic integrity of the subducted basalt and harzburgite

\footnotetext{
* Corresponding author

Email address: fmunch@seismo.berkeley.edu (Federico D. Munch)

${ }^{1}$ Institute of Geophysics, ETH Zurich, Switzerland.

${ }^{2}$ Institute of Theoretical Physics, University of Zurich, Switzerland.

${ }^{3}$ Laboratoire de Géologie de Lyon, Terre, Planètes, Environnement, Université de Lyon,

${ }^{4}$ Research School of Earth Sciences, Australian National University, Australia.
}

Present address: Berkeley Seismological Laboratory, University of California, Berkeley, CA 94720, USA. Ecole Normale Supérieure de Lyon, CNRS, France.
\end{abstract}


may be better preserved for geologically significant times underneath cratonic regions.

Keywords: Mantle thermo-chemistry, receiver functions, surface wave dispersion, petrologic phase equilibrium calculations

\section{Introduction}

Since the recognition that plate tectonics is driven by solid-state mantle convection in the late 1960 s, geoscientists have been debating mantle thermochemical structure and the detailed morphology of convection. Geochemical analysis of volcanic rocks (e.g., Pearson et al., 2003) support the existence of distinct reservoirs suggesting the mantle to be compositionally and dynamically layered, with the $660-\mathrm{km}$ seismic discontinuity acting as compositional boundary. However, three-dimensional images of mantle structure from seismic tomography (e.g., French and Romanowicz, 2014, Schaeffer and Lebedev, 2013) indicate that subducted oceanic plates (known as slabs) can penetrate into the lower mantle as well as stagnate in the mantle transition zone (MTZ; region between 410 and $660 \mathrm{~km}$ depth) and around $\sim 1000 \mathrm{~km}$ depth, which rules out global layering at $660-\mathrm{km}$ and appears to support whole-mantle convection instead. A range of hypotheses have been proposed to reconcile these observations (e.g., leaky layering at $660 \mathrm{~km}$, layering deeper in the mantle, and ubiquitous compositional heterogeneity), yet the detailed morphology of convection patterns remains a matter of debate. The key question is whether the $660-\mathrm{km}$ discontinuity is caused by a change in chemical composition (e.g., Anderson, 2007 ) in addition to the endothermic ringwoodite $\rightarrow$ bridgmanite + ferropericlase phase transition (e.g., Ita and Stixrude, 1992).

Numerical modeling of subduction suggests that a lower-mantle enrichment in basalt ( $\sim 8 \%$ with respect to the upper mantle) can explain slab stagnation at 660 and $1000 \mathrm{~km}$ depth, in the presence of whole-mantle convection (e.g., Ballmer et al. 2015). This finding suggests that mantle convection occurs in an intermittent mode between layered- and whole-mantle convection, where slabs 
penetrate intermittently in space and time, while a globally-averaged compositional stratification at $660 \mathrm{~km}$ depth is maintained (e.g., Tackley, 2000). Supporting evidence arises from direct comparison of one-dimensional Earth reference velocity models and seismic observations sensitive to the bulk velocity structure of the mantle (P- and S-wave travel times and surface wave data) with estimates for a pyrolitic (Ringwood, 1975) and adabatic mantle based on insights obtained from theoretical and experimental mineral physics. These studies report that pyrolitic and adiabatic mantle models cannot explain global observations (e.g., Cobden et al., 2008) and suggest that the lower mantle is either enriched (e.g., Murakami et al., 2012) or depleted (e.g., Khan et al., 2008 in silicon relative to the upper mantle. However, detailed analysis of SS and PP precursors that are sensitive to MTZ discontinuities, indicate that the observed amplitude variations (and even the absence of PP precursors in certain regions) are well-explained by lateral changes in mantle temperature or aluminium content for a pyrolite mantle (Deuss et al., 2006).

Here, we investigate whether compositional mantle stratification is required to jointly explain seismic data sensitive to upper mantle and transition zone beneath a number of different tectonic settings by implementing a methodology that interfaces geophysical inversion of seismic data with self-consistent calculations of mineral phase equilibria (Munch et al. 2018). The prediction of rock mineralogy and its elastic properties as a function of pressure, temperature, and bulk composition allows for self-consistent determination of depth and sharpness of the 410 - and $660-\mathrm{km}$ seismic discontinuities as well as upper mantle velocities. This enables the joint analysis of P-to-s receiver functions and Rayleigh surface wave dispersion data to directly infer global lateral variations of mantle temperature and composition. Until now, both data types have never been combined to resolve the structure down to the base of the MTZ. 
54

\subsection{P-to-s receiver functions}

P-to-s receiver functions (hereinafter RF) are the records of compressional waves that convert into shear waves when encountering a discontinuity in material properties and are sensitive to sharp seismic discontinuities within a depthdependent annulus underneath seismic stations (see Figure 1). Conversions occurring at the $410-\mathrm{km}(\mathrm{P} 410 \mathrm{~s})$ and $660-\mathrm{km}(\mathrm{P} 660 \mathrm{~s})$ discontinuities are routinely used for detection of mineralogical phase changes at 410 and $660 \mathrm{~km}$ depth (e.g., Helffrich, 2000 Lawrence and Shearer, 2006b; Tauzin et al., 2008), but are rarely inverted to determine MTZ elastic structure (e.g., Schmandt, 2012 Lawrence and Shearer, 2006a). Building on previous experience (Munch et al. 2018), we here invert RF waveforms to directly map global variations in mantle temperature and composition.

To this end, we first constructed a new global high-quality dataset of RF waveforms. The data consists of three-component seismograms recorded at 155 broad-band permanent stations between 1997 and 2018. In order to ensure a good signal-to-noise ratio, only teleseismic events for epicentral distances between $40^{\circ}$ and $95^{\circ}$ with magnitudes larger than 6 were selected. RF waveforms at each station were obtained by: 1) filtering of the records in the period range 1-100 s; 2) rotation of the seismograms into radial, transverse, and vertical components; 3) calculation of signal-to-noise ratio between the maximum amplitude of the signal and the averaged root-mean-square of the vertical component; 4) construction of RF waveforms through iterative time domain deconvolution (Ligorria and Ammon, 1999) for traces with signal-to-noise ratio larger than 5; and 5) low-pass filtering of the RF waveforms to remove frequencies higher than $0.2 \mathrm{~Hz}$. Finally, RF waveforms were corrected for move-out (using IASP91 velocity model and a reference slowness of $6.5 \mathrm{~s} / \mathrm{deg}$ ) and subsequently stacked. Error on the stacked amplitudes were estimated using a bootstrap resampling approach (Efron and Tibshirani, 1991). 


\subsection{Data selection}

The inversion of RFs requires careful waveform inspection to ensure high quality data. The stations were classified into three quality classes by visual inspection of the stacked RF waveforms (see Figure 2 and Table S1). Type-A stations correspond to RF waveforms with high signal-to-noise ratio and clear P410s and P660s signals. Type-B stations are characterized by RF waveforms with high signal-to-noise ratio but the signals corresponding to either the P410s or P660s conversions cannot be clearly isolated due to the potential presence of interfering seismic phases or complex three-dimensional structure. Type-C stations correspond to locations where only a small number of data could be stacked resulting in highly noisy RF waveforms with no clear P410s and P660s signals.

We found 48 stations for which the signals corresponding to either the P410s or P660s conversions cannot be unambiguously isolated (Type-B stations in Figure 2 and Figure S1). These stations are often located in regions where structure has previously been identified in seismic tomography models (e.g., Schaeffer and Lebedev, 2013) such as subducted slabs in northeast Asia and the Mediterranean Sea. Our analysis focuses on 103 stations (Type-A stations in Figure 2 mainly located away from plate boundaries, where the RF waveforms can be accurately modeled with relatively low computational cost by methods that simulate full seismic wave propagation from source to receiver in spherical 1D Earth models.

\subsection{Rayleigh wave dispersion data}

Rayleigh wave phase velocities are sensitive to the bulk velocity structure of the upper mantle and provide a better global coverage than the RFs, but with lower lateral resolution $(\sim 650 \mathrm{~km})$. Here, we enhanced our RF data by extracting phase velocity dispersion curves for each station from the most recent available global data set of Rayleigh wave phase velocity dispersion (Durand

et al. 2015). The data set consists of 60 phase velocity maps and uncertainties 


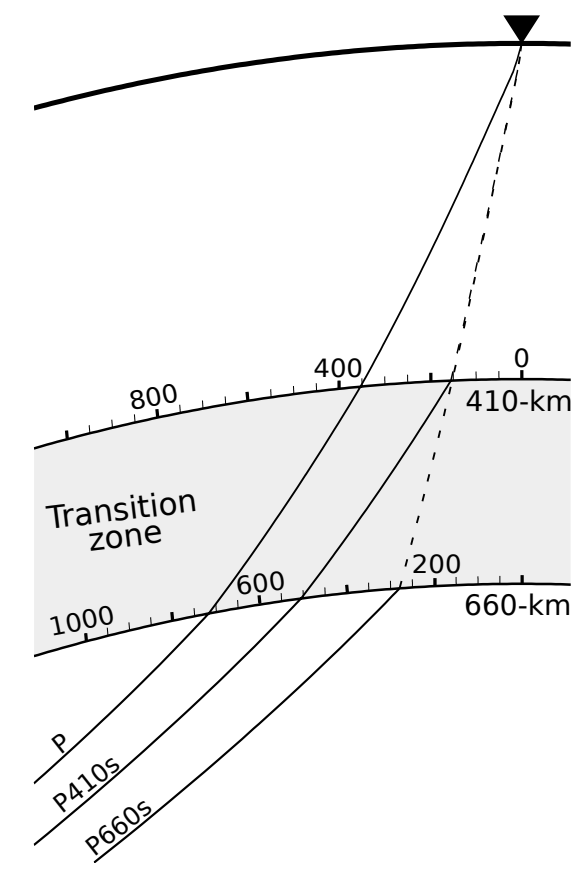

Figure 1: Schematic representation of teleseismic $\mathrm{P}-$ to-s waves scattered in the mantle transition zone and recorded at a seismic station (black triangle) located at an epicentral distance of $40^{\circ}$. Solid and dashed lines correspond to $\mathrm{P}$ and $\mathrm{S}$ ray path segments, respectively. The distance from the receiver along the $410-\mathrm{km}$ and $660-\mathrm{km}$ discontinuities is indicated in kilometers. The conversion points at $410-\mathrm{km}$ and $660-\mathrm{km}$ depth are laterally shifted from the station by $\sim 150 \mathrm{~km}$ and $\sim 250 \mathrm{~km}$, respectively. Figure modified from Tauzin et al. (2008). 

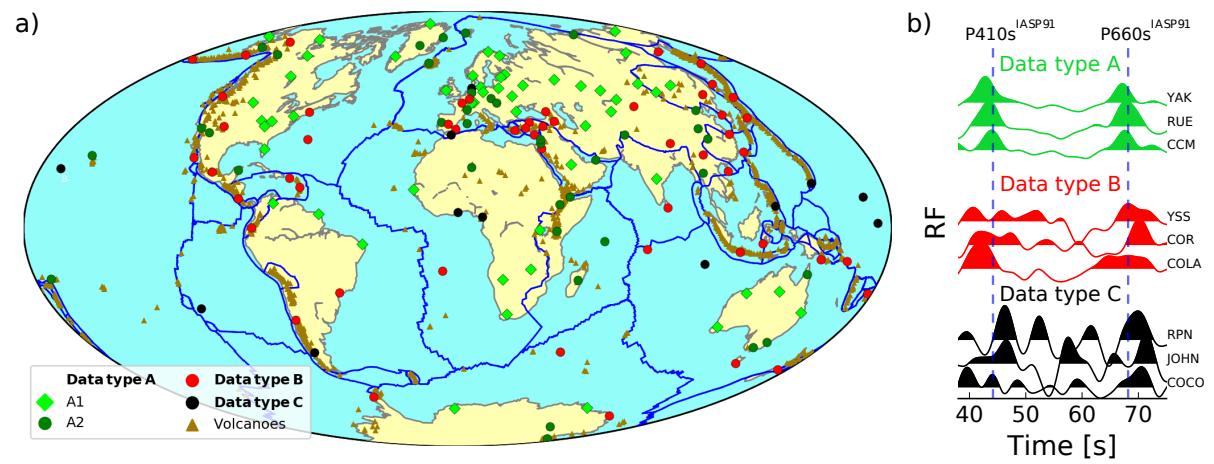

Figure 2: Geographic distribution of seismic stations. a) In all 155 seismic stations were considered and classified by data quality (type A, B, and C). Type A stations are subdivided into two further categories based on the data fit, labelled "A1" and "A2". b) Examples of observed receiver functions $(\mathrm{RF})$ for each data class.

covering the period range $40-250 \mathrm{~s}$ for the fundamental mode and up to the fifth overtone on a $2^{\circ} \times 2^{\circ}$ grid.

We would like to note that this data set is the result of a global tomographic inversion and hence is affected by the chosen regularization. If overly damped, phase velocity maps will be smoothened as a result of which dispersion curves and RF waveforms might possibly sense slightly different structure.

\subsection{Model parameterization and forward problem}

The crustal structure underneath each station is described in terms of a set of layers with variable $\mathrm{S}-$ wave velocity $\mathrm{V}_{\mathrm{s}}^{\mathrm{i}}$ and thickness $\mathrm{d}^{\mathrm{i}}(\mathrm{i}=1, \ldots, 5)$. Mantle velocities below the Moho are derived from a set of model parameters that describe mantle composition and thermal structure (Munch et al., 2018). The former is parameterized in terms of a single variable (f) that represents the amount of basalt in a basalt-harzburgite mixture, with the composition of basalt and harzburgite end-members described using the CFMASNa chemical model system comprising the oxides $\mathrm{CaO}-\mathrm{MgO}-\mathrm{FeO}-\mathrm{Al}_{2} \mathrm{O}_{3}-\mathrm{SiO}_{2}-\mathrm{Na}_{2} \mathrm{O}$. Mantle thermal structure is delineated by a conductive lithosphere (linear gradient) on top of an adiabatic geotherm. The lithospheric temperature is defined by the 
temperature $\left(\mathrm{T}_{0}\right)$ at the surface and the temperature $\left(\mathrm{T}_{\text {lit }}\right)$ at the bottom of the lithosphere. The bottom of the lithosphere $\left(\mathrm{z}_{\mathrm{lit}}\right)$ corresponds to the depth at which the conductive lithospheric geotherm intersects the mantle adiabat defined by the entropy of the lithology at the temperature $T_{\text {lit }}$ and pressure $P_{\text {lit }}$. This simplification allow us to treat continents as conducting lids that float atop the convecting mantle. The pressure profile is obtained by integrating the load from the surface.

Mantle mineralogy and its elastic properties as a function of depth are computed by means of free-energy minimization (Connolly, 2009; Stixrude and Lithgow-Bertelloni, 2011). Furthermore, shear attenuation is self-consistently derived from the shear modulus, temperature, and pressure profiles using the extended Burgers viscoelastic model (e.g., Bagheri et al., 2019). The resulting velocity and attenuation profiles are then used to compute synthetic RF waveforms and Rayleigh wave phase velocities. The former are computed with the reflectivity method (Muller, 1985) replicating the slowness distribution recorded at each station and the same processing scheme applied on the observed seismograms. The latter are estimated using a spectral element-based python toolbox (Kemper et al., 2020; A spectral element normal mode code for the generation of synthetic seismograms; manuscript in preparation).

The choice of chemical model parameterization relies on its proximity to mantle dynamical processes, i.e., partial melting of mantle material along midocean ridges. This process produces a basaltic crust and its depleted residue (harzburgite), which are cycled back into the mantle at subduction zones and become entrained in the mantle flow and remixed. In spite of its simplicity, the concept of distinct chemical end-member compositions has been found to provide an adequate description of mantle chemistry, at least from a geophysical point of view (e.g., Xu et al., 2008; Khan et al., 2009, Ritsema et al., 2009). Furthermore, the use of the CFMASNa model chemical system allows us to account for the effect of transitions in the olivine, garnet, and pyroxene components of the mantle. As a consequence, and in contrast to usual seismological practice (e.g., Lawrence and Shearer, 2006b; Tauzin et al., 2008, Schmandt 
2012 Cottaar and Deuss, 2016), estimates of MTZ topography, volumetric velocities, and temperature derived here are independent of tomographic models or assumptions about the Clapeyron slope of pure $(\mathrm{Mg}, \mathrm{Fe})_{2} \mathrm{SiO}_{4}$-phases.

The thermodynamic model presented here precludes consideration of redox effects (e.g., Cline II et al., 2018) as well as minor phases and components such as $\mathrm{H}_{2} \mathrm{O}$ and melt due to lack of thermodynamic data. With regard to potential errors introduced by neglecting the effect of water, experimental evidence suggests that the presence of water would tend to thicken the transition zone by moving the olivine-wadsleyite transition up, while deepening the dissociation of ringwoodite (Frost and Dolejš , 2007, Ghosh et al., 2013). However, as discussed by Thio et al. (2015), it is currently not possible to quantify the effect of water on phase transitions because of the large uncertainties in thermodynamic data. In addition, the analyses performed by Thio et al. (2015) and Wang et al. (2018), where it is suggested that hydration of ringwoodite can significantly reduce elastic wave velocities, are based on experiments performed at ambient pressure conditions. A recent study by Schulze et al. (2018) showed that the hydration-induced reduction of seismic velocities almost vanishes at the temperature and pressure conditions of the transition zone. Density and elastic moduli are estimated to be accurate to within $\sim 0.5 \%$ and $\sim 1-2 \%$, respectively (Connolly and Khan, 2016).

\subsection{Inverse problem}

The inverse problem is solved within a Bayesian framework where the solution is described in terms of the posterior probability distribution $\sigma(\mathbf{m} \mid \mathbf{d}) \propto$ $\rho(\mathbf{m}) \mathcal{L}(\mathbf{m} \mid \mathbf{d})$. The probability distribution $\rho(\mathbf{m})$ describes the a priori information on model parameters (summarized in Table S2) and the likelihood function $\mathcal{L}(\mathbf{m} \mid \mathbf{d})$ represents a measure of the similarity between the observed data $\mathbf{d}$ and the predictions from model $\mathbf{m}=\left(\mathrm{T}_{\text {lit }}, \mathrm{z}_{\text {lit }}, \mathrm{f}, \mathrm{V}_{\mathrm{s}}^{1}, \ldots, \mathrm{V}_{\mathrm{s}}^{5}, \mathrm{~d}_{1}, \ldots, \mathrm{d}_{5}\right)$. As time windows containing considerably small or no signal can introduce undesirable noise into the misfit function and unnecessarily increase the complexity of the misfit surface (Munch et al. 2018), the modeled and observed RF waveforms 
are compared in three time windows defined by visual inspection of the observed waveforms to include: 1) crustal signals $(-5 \mathrm{~s}<t<30 \mathrm{~s}) ; 2)$ the P410s conversion (generally observed in the time window $40 \mathrm{~s}-50 \mathrm{~s}$ ); and 3 ) the P660s conversion (typically recorded within the time window $60 \mathrm{~s}-80 \mathrm{~s}$ ). Consequently, the likelihood function can be written as

$$
\mathcal{L}(\mathbf{m} \mid \mathbf{d}) \propto \exp \left\{-\frac{1}{2} \sum_{\mathrm{i}=1}^{3} \phi_{\mathrm{i}}^{\mathrm{RF}}(\mathbf{m} \mid \mathbf{d})-\frac{1}{2} \sum_{\mathrm{i}=0}^{5} \phi_{\mathrm{i}}^{\mathrm{SW}}(\mathbf{m} \mid \mathbf{d})\right\}
$$

with

$$
\phi_{\mathrm{i}}^{\mathrm{RF}}(\mathbf{m} \mid \mathbf{d})=\frac{1}{3 \mathrm{~N}_{\mathrm{i}}} \sum_{j=1}^{\mathrm{N}_{\mathrm{i}}}\left[\frac{\mathrm{RF}^{\text {observed }}\left(t_{j}\right)-\mathrm{RF}^{\text {modeled }}\left(\mathbf{m}, t_{j}\right)}{\delta \mathrm{RF}^{\text {observed }}\left(t_{j}\right)}\right]^{2}
$$

and

$$
\phi_{\mathrm{i}}^{\mathrm{SW}}(\mathbf{m} \mid \mathbf{d})=\frac{1}{6 \mathrm{M}_{\mathrm{i}}} \sum_{j=1}^{\mathrm{M}_{\mathrm{i}}}\left[\frac{\mathrm{C}_{\mathrm{p}}^{\mathrm{i}, \text { observed }}\left(T_{j}\right)-\mathrm{C}_{\mathrm{p}}^{\mathrm{i}, \text { modeled }}\left(T_{j}, \mathbf{m}\right)}{\delta \mathrm{C}_{\mathrm{p}}^{\mathrm{i}, \text { observed }}\left(T_{j}\right)}\right]^{2},
$$

where $\mathrm{C}_{\mathrm{p}}^{\mathrm{i}}\left(T_{j}\right)$ denotes Rayleigh wave phase velocities for mode $\mathrm{i}$ and period $T_{j}$ with $\mathrm{M}_{\mathrm{i}}$ being the number of observed periods for each mode, $\delta$ observed uncertainties for each data type, and $\mathrm{N}_{\mathrm{i}}$ the number of samples in each time window of interest.

We sample the posterior distribution in the model space by combining a Metropolis-Hastings Markov chain Monte Carlo (McMC) method (e.g., Mosegaard and Tarantola, 1995) with a stochastic optimization technique (Hansen et al. 2011). The latter is used to obtain a good initial model for the McMC algorithm. This strategy improves the efficiency of the McMC method by significantly reducing the burn-in period. The McMC sampling is performed using 10 independent chains (with a total length of 10,000 iterations) characterized by identical initial models but different randomly chosen initial perturbations. This strategy allows for sampling 100,000 models with moderate computational cost ( $\sim 3$ days using 10 cores). Finally, the 50,000 best-fitting candidates are used to build histograms of the marginal probability distribution of each model parameter. 


\section{Results}

The seismic data are inverted using a Bayesian framework to provide estimates of model range and uncertainty (see Sections 2.4 and 2.5). At each station, we recover marginal probability distributions of parameters describing crustal and mantle thermo-chemical structure (Figure $3 \mathrm{~b}$ ). By-products are associated elastic profiles ( $\mathrm{Vp}, \mathrm{Vs}$, and density) for the upper mantle down to $1000 \mathrm{~km}$ depth (Figure 3b). The sampled models must predict the observed Rayleigh wave phase velocities for the fundamental mode and overtones, as well as the main features of the observed RF waveforms (Figure 3 a). Type-A stations are further separated into two categories based on the quality of the data fit (Figure 2a) determined by visual inspection of the RF waveforms (Figure 3 . and Figure S1) and Rayleigh wave dispersion curves (Figures S2-S3).

Our results suggest significant regional deviations from a compositionally uniform and adiabatic mantle. The retrieved models succeed in explaining the observed data in the inner part of continents (A1 stations in Figure $2 \mathrm{a}$ ), but not near active plate boundaries such as in the western US or northeast Eurasia, in oceanic regions (Hawaii, Iceland, Samoa), or regions of intra-plate volcanism such as the Afar (A2 stations in Figure 2a). Among 93 stations in the continents, we succeed to fit the seismic data at 53 stations: 11 stations in Phanerozoic provinces of age younger than 600 Myr, 20 stations in 600-2000 Myr old precambrian platforms, and 22 stations in cratonic regions older than 2.2 Byr (Figure 4 a).

We find mantle potential temperatures - equivalent to the temperature that the mantle would have at the surface, if it ascended along an adiabat without undergoing melting (McKenzie and Bickle, 1988) - ranging between 1450$1700 \mathrm{~K}$ (Figure 4b). These estimates are in good agreement with experimentally determined mantle potential temperatures $(1610 \pm 35 \mathrm{~K})$ based on a pyrolitic composition (Katsura et al., 2010) and estimates derived from petrological and geochemical analysis of erupted lavas (1553-1673 K; Herzberg et al., 2007). Furthermore, we find that cratonic regions are characterized by low mantle po- 
a)
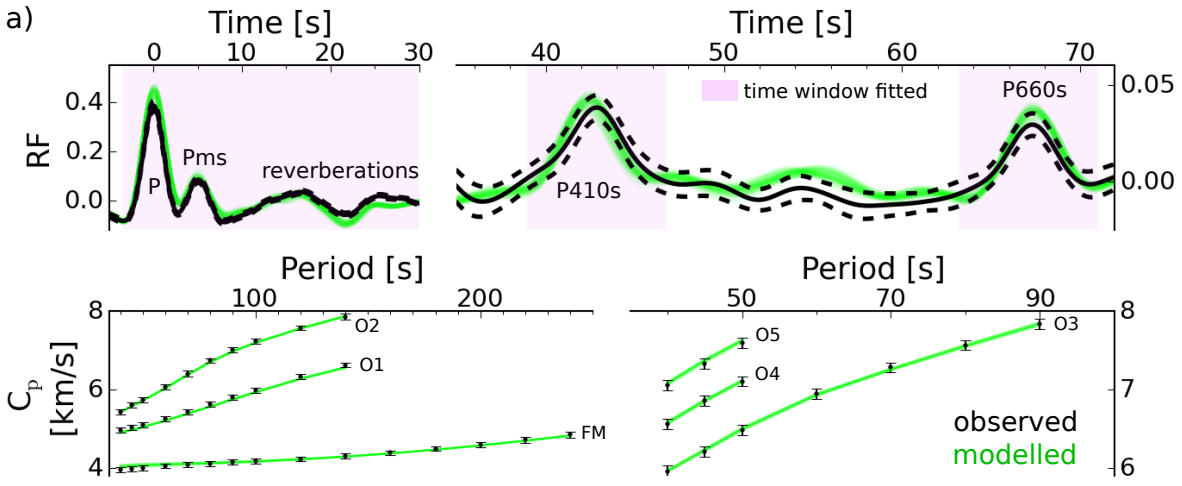

b)

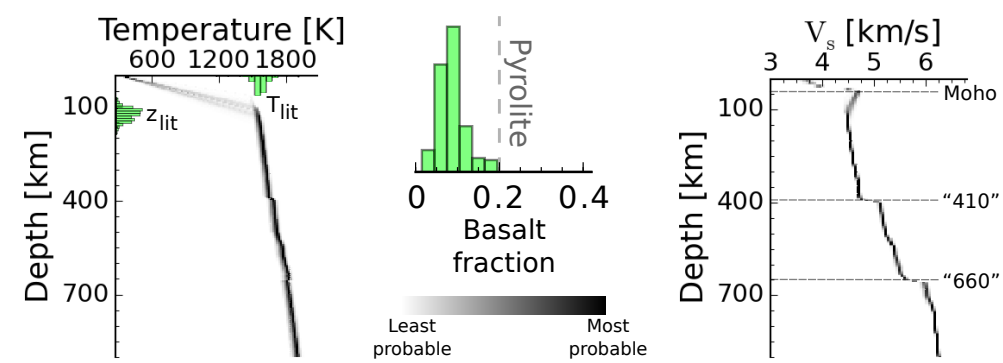

c)

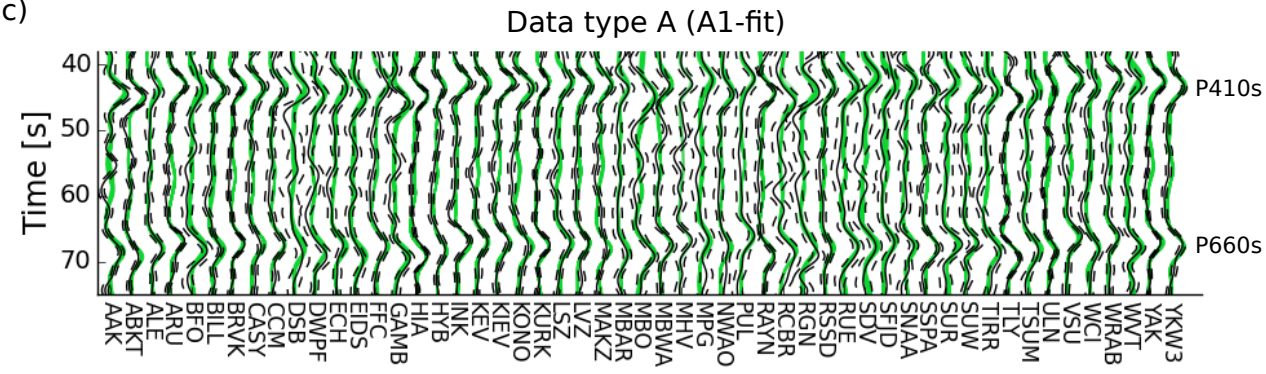

Figure 3: a) Example data fit (at station YAK) of RF waveforms and fundamental mode (FM) and overtone $(\mathrm{O})$ Rayleigh wave phase velocities $\left(\mathrm{C}_{\mathrm{p}}\right)$. Observed data are shown in black and predictions in green. Magenta rectangles indicate the part of the RF waveform that is fitted in the inversion. b) Example inverted composition, thermal (temperature), and shear-wave velocity $\left(\mathrm{V}_{\mathrm{s}}\right)$ structure, including marginal posterior distributions of the main thermo-chemical parameters basalt fraction, lithospheric thickness $\left(z_{l i t}\right)$ and temperature $\left(T_{\text {lit }}\right)$. c) Observed (black) and computed (green) RF waveforms for A1-fit stations (RF waveforms for A2-fit stations are shown in Figure S1). 


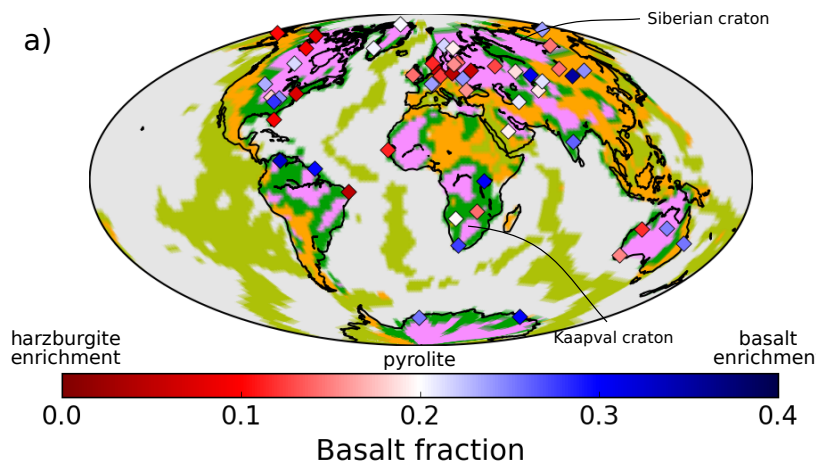

b)
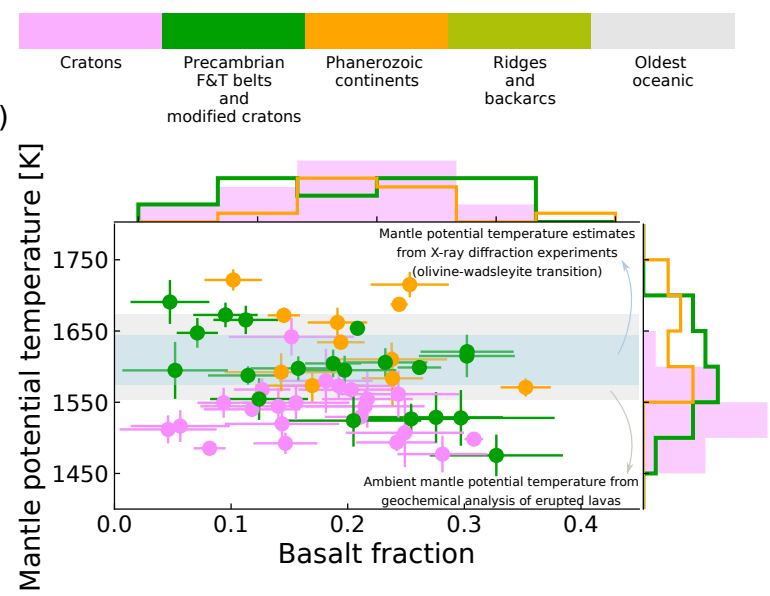

C)

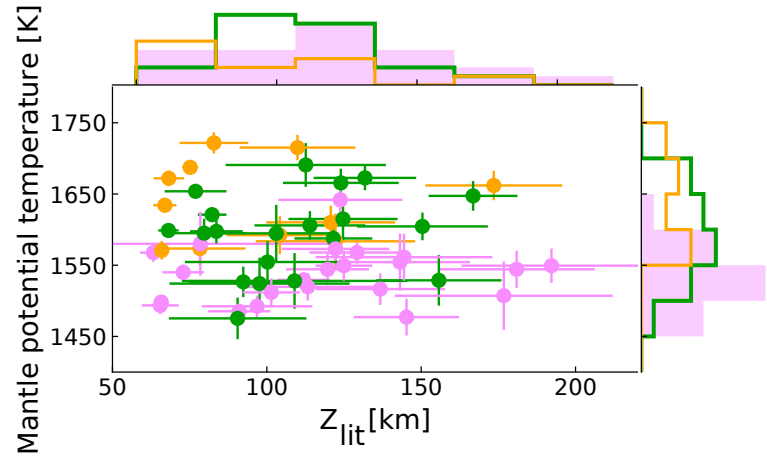

Figure 4: Global variations in mantle composition and thermal state. The results summarise the models that best fit (equivalent to the most probable model from the entire sampled model distribution) the observed data at each station and include both fully equilibrated as mechanically mixed models (see Figure 7). Panel a) depicts lateral variations in mantle composition (basalt fraction) for A1-fit stations (indicated by diamonds in Figure 2a). Coloured background shows a regionalised tectonic map derived from cluster analysis of tomographic models (Schaeffer and Lebedev 2015). Panels b) and c) summarize most probable mantle potential temperature, basalt fraction, and thizkness of the conductive layer $\left(\mathrm{z}_{\text {lit }}\right)$ estimates classified by tectonic setting and shown as dots including error bars and along the axes as distributions. Coloured areas in panel b) depict experimentally-determined mantle potential temperatures for a pyrolitic composition (light blue, Katsura et al. 2010) and estimates derived from petrological and geochemical analysis of erupted lavas (yellow, Herzberg et al. 2007). 

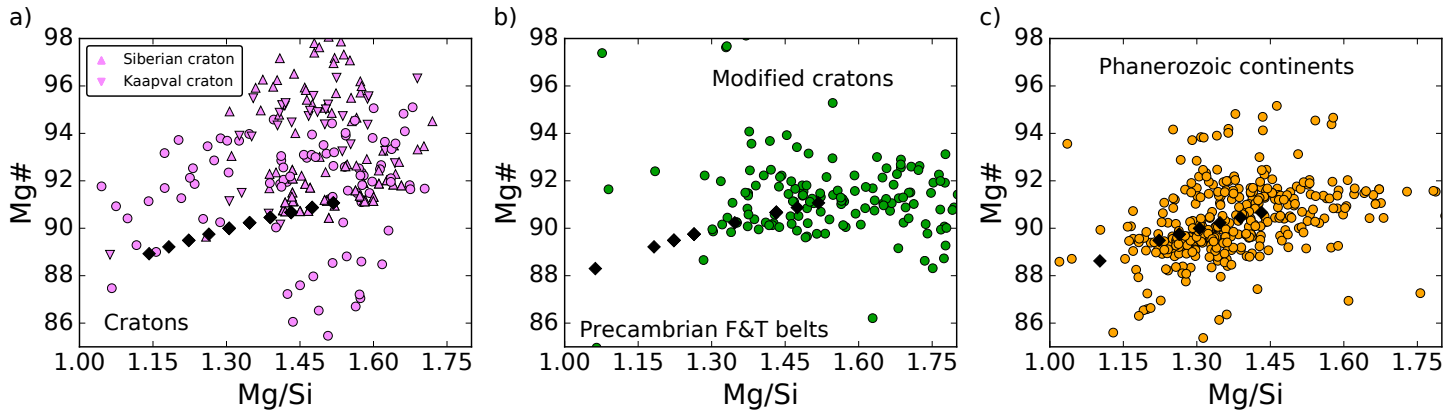

Figure 5: Variability in $\mathrm{Mg} \#(\mathrm{Mg} /(\mathrm{Mg}+\mathrm{Fe}))$ and $\mathrm{Mg} / \mathrm{Si}$ inferred in this study (black diamonds) and estimates derived from analysis of mantle xenoliths (coloured circles) extracted from the GEOROC database (http://georoc.mpch-mainz.gwdg.de) for different tectonic settings: a) cratonic regions; b) Precambrian fold-thrust belts; and c) phanerozoic continents based on the tectonic regionalization of Schaeffer and Lebedev (2015).

tential temperatures (1450-1550 K) and significant lateral variability in mantle composition ( $f \sim 0.05-0.30)$, whereas higher mantle potential temperature estimates (1600-1700 K) and smaller deviations from a pyrolitic mantle composition (f $\sim 0.1-0.25)$ are recovered underneath phanerozoic continents (see Figure $4 \mathrm{~b}$ ). In addition, we find that phanerozoic regions are characterized by relatively thin thermal conductive layers (mean $\mathrm{z}_{\text {lit }} \sim 75 \mathrm{~km}$ ), whereas larger thicknesses (mean $\mathrm{z}_{\text {lit }} \sim 135 \mathrm{~km}$ ) are inferred underneath cratonic regions (Figure 4 c).

The variability in mantle composition is in overall agreement with geochemical observations that derive from analysis of mantle xenoliths - mantle fragments carried to the surface by explosive eruptions - in the form of $\mathrm{Mg} \#$ $(\mathrm{Mg} /(\mathrm{Mg}+\mathrm{Fe}))$ and $\mathrm{Mg} / \mathrm{Si}$ estimates (see Figure 5), particularly for Precambrian fold-thrust belts (F\&T belts) and Phanerozoic continents. Mantle xenoliths from Archean regions, in particular the Siberian and Kaapval cratons (indicated in Figure 4 a), are characterized by an excess in $\mathrm{SiO}_{2}$. This Si-enrichment was first believed to be a general characteristic of Archean subcontinental mantle (e.g., Boyd et al., 1997). However, lower $\mathrm{SiO}_{2}$ concentrations were measured in xenoliths from the Slave (e.g., Kopylova and Russell, 2000) and North Atlantic (e.g., Bernstein et al., 1998) cratons suggesting that Si-enrichment is a 


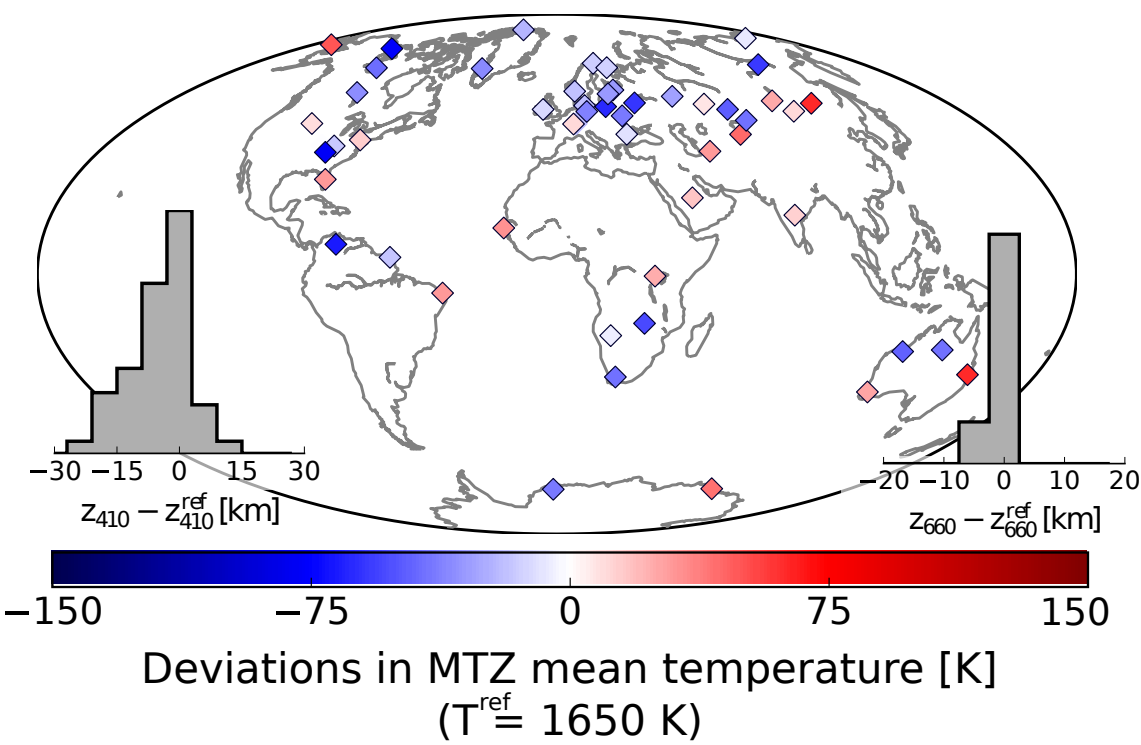

Figure 6: Relative lateral variations in mean mantle transition zone (MTZ) temperature and discontinuity topography (histograms). The latter show changes in the "410-" and "660-km" seismic discontinuities that bound the transition zone.

secondary (metasomatic) feature imposed upon the subcontinental mantle after its formation as a residue of melting (Carlson et al. 2005). The compositional changes imposed by such metasomatic processes can be addressed by extending the chemical model to include other plausible end-members such as lherzolitic and dunitic components.

In agreement with previous global studies (e.g., Deuss et al., 2013), we determine an average MTZ thickness of $\sim 250 \mathrm{~km}$ with regional variations between $235 \mathrm{~km}$ and $270 \mathrm{~km}$ that mainly reflect changes in the topography of the 410-km discontinuity (Figure 6). Furthermore, our results indicate that MTZ thickness is linearly correlated with MTZ temperatures, whereas no clear correlation with mantle composition can be identified (Figure S4). In addition, the recovered crustal structure is in overall agreement with global crustal models (see Figure S5).

In order to test the robustness of the thermo-chemical variations reported here, we performed two additional sets of inversions in which we fixed: 1) mantle 
composition to pyrolite $(\mathrm{f}=0.2)$; and 2 ) mantle thermal parameters $\left(\mathrm{T}_{\text {lit }}=\right.$ $1623 \mathrm{~K}$ and $\left.\mathrm{z}_{\text {lit }}=100 \mathrm{~km}\right)$. We find that data are better explained $(\sim 2-15$ $\%$ reduction in misfit values) when both thermal and compositional variations are considered (Figure S6). Furthermore, we find that it is not possible to explain the observed data solely by compositional variations (Figure S6c). This analysis confirms that although temperature plays a primary role in determining the seismic structure of the upper mantle and transition zone, the effect of composition cannot be neglected.

In addition, we investigated the correlation between the thermochemical parameters inverted for here (Figure S7). As reported in previous work (Munch et al. 2018), no significant trade-offs are found between thermal and compositional parameters signaling that temperature and composition are independently resolvable. In the context of erroneously mapping shallow into deeper structure, one could envisage mapping fast lithospheric phase velocities into cold temperatures. As a result, lower mantle temperatures would ensue, which correspond to larger MTZ thicknesses, and thus increased differential RF travel times. To compensate, a systematic decrease in basalt fraction would be required (see Figure 5 in Munch et al., 2018), which would result in a strong correlation between mantle potential temperature and basalt fraction in the subcontinental mantle. Such a correlation is, however, not observed (see Figure 4 b) indicating that shallow cold continental structure is unlikely to be mapped into MTZ structure.

\section{Discussion and implications}

Mineralogical models of the Earth typically view the mantle as either homogeneous and pyrolitic (e.g., Ringwood, 1975) or chemically stratified with homogeneous and equilibrated compositions in each layer (e.g., Mattern et al., 2005). To first order, such models are capable of explaining the observed composition of mid-ocean ridge basalts (e.g., McKenzie and Bickle, 1988) and seismic velocities of the upper mantle and transition zone (e.g., Ita and Stixrude, 1992). How- 
ever, experimental measurements of mantle mineral chemical diffusivity (e.g., Hofmann and Hart, 1978) suggest that equilibration may not be accomplished over the age of the Earth for the amount of stretching and folding predicted in mantle convection simulations (e.g., Nakagawa and Buffett, 2005). Furthermore, trace element chemistry of basalts (Sobolev et al. 2007) also point to the mantle as consisting of a non-equilibrated mechanical mixture. This led to the concept of two distinct mantle compositional models (Xu et al., 2008): mechanical mixture and equilibrium assemblage. The former represents the scenario in which pyrolitic mantle has undergone complete differentiation to basaltic and harzburgitic rocks, whereas the latter assumes the mantle to be well-mixed and fully-equilibrated. These two types of mantle compositional models generate subtle differences that are rarely accounted for in the interpretation of seismic data (e.g., Ritsema et al., 2009).

Here, we have investigated the extent to which the mantle is well-mixed or chemically equilibrated by quantitatively comparing the quality of the data fit obtained for each compositional model. We find 42 stations for which relative differences in the misfit values for the best-fitting models (calculated as described in Section 2.5 are larger than 5\% (Figure S8). Our results suggest that the mantle is neither completely equilibrated nor fully mechanically mixed, but appears to be best described by an amalgam between the two with cratonic regions best characterized by a mechanically mixed model and Precambrian fold-thrust belts best described by an equilibrium assemblage (see Figure 77). This suggests that the lithologic integrity of the subducted basalt and harzburgite is better preserved for geologically significant times beneath stable cratonic regions, i.e., chemical equilibration is more difficult to achieve. Further to this, the presence of lower potential mantle temperatures underneath cratonic regions support the existence of deep low-temperature continental roots whose signal extends into the MTZ (e.g., Jordan, 1978) and which might be isolated from the main mantle flow associated with ridges and trenches. In contrast hereto, our results suggest that these regions are not systematically depleted in basalt component. 
a)

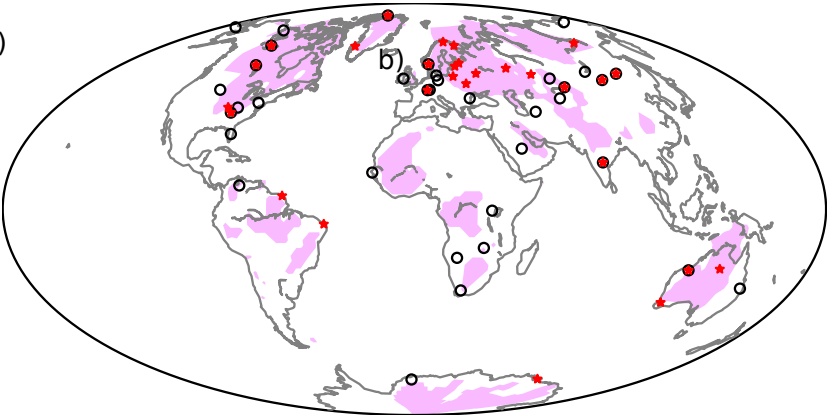

$\star$ Mechanically-mixed mantle $\bigcirc$ Fully-equilibrated mantle

b)
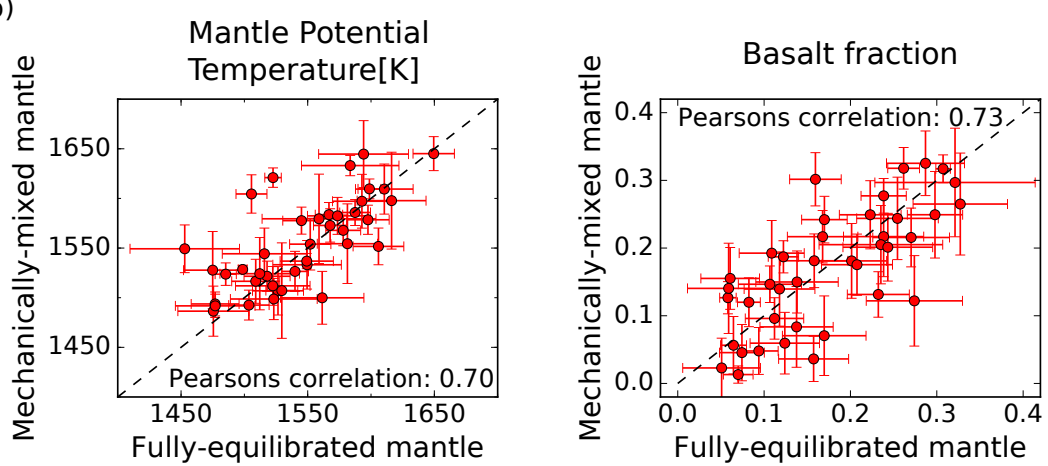

Figure 7: a) Global map of cratonic regions (pink areas) and distribution of stations for which the observed data are best explained by either a mechanically mixed or a fully equilibrated mantle compositional model. b) Most probable mantle potential temperature and basalt fraction estimates (shown as dots including error bars) retrieved for fully-equilibrated and mechanically-mixed mantle models. 
Despite subtle differences, we find that temperature and compositional estimates appear to be independent of compositional model (Figure 7b). This contrasts with a previous study (Ritsema et al. 2009 ) where the equilibrium assemblage model was found to result in higher temperature estimates relative to the mechanical mixture model based on comparison of theoretical and observed differential travel times of waves reflected underneath the MTZ discontinuities. This discrepancy can be explained by the fact that Ritsema et al. (2009) 1) only considered a pyrolitic mantle composition and therefore mapped all variations of chemistry into temperature and 2) focused on regions of the mantle characterized by higher mantle potential temperatures $(>1700 \mathrm{~K})$ for which differences in differential travel times predicted for distinct mantle compositional models are observed to be larger (cf. Figure 5 in Munch et al., 2018).

Laboratory experiments and numerical simulations of mantle convection suggest that continents can have a strong influence on mantle dynamics and the heat flow escaping from the Earth's surface (e.g., Lenardic et al., 2011). In this context, it has been proposed that continents can act as thermal insulators by inhibiting heat loss, thereby increasing mantle temperatures regionally (e.g., Ballard and Pollack, 1987; Lenardic et al., 2005). For instance, Rolf et al. (2012) predicted a temperature increase of $\sim 140 \mathrm{~K}$ underneath continental regions relative to the sub-oceanic mantle, based on internally heated 3-D mantle convection simulations with various continental configurations. However, the influence of the insulating effect of continents on present-day mantle thermal state remains uncertain (cf, Jain et al., 2019). The mantle potential temperatures derived here (summarized in Figure $4 \mathrm{~b}$ ) suggest that the insulating effect might not be as prominent as predicted in mantle convection simulations.

A recent analysis of short-scale $(\sim 10 \mathrm{~km})$ variations in $660-\mathrm{km}$ discontinuity topography (Wu et al. 2019) suggested the potential existence of chemical layering at the top of the lower mantle. In this context, our results indicate that a compositional boundary at $660 \mathrm{~km}$ depth is not required beneath stable continental regions to explain the observed seismic signals. However, we find significant complexity in the RF waveforms (see Figure S1) recorded near ac- 

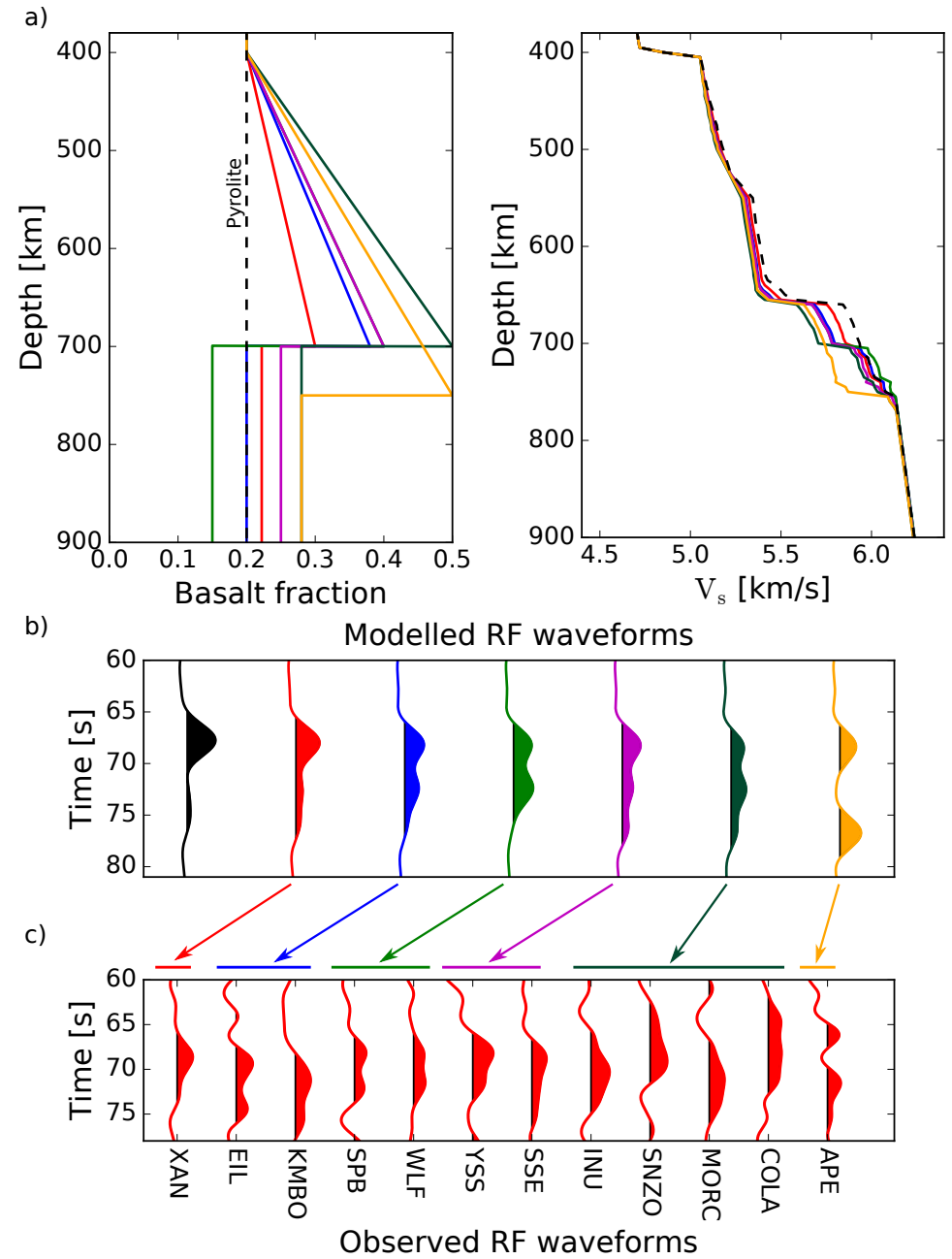

d)

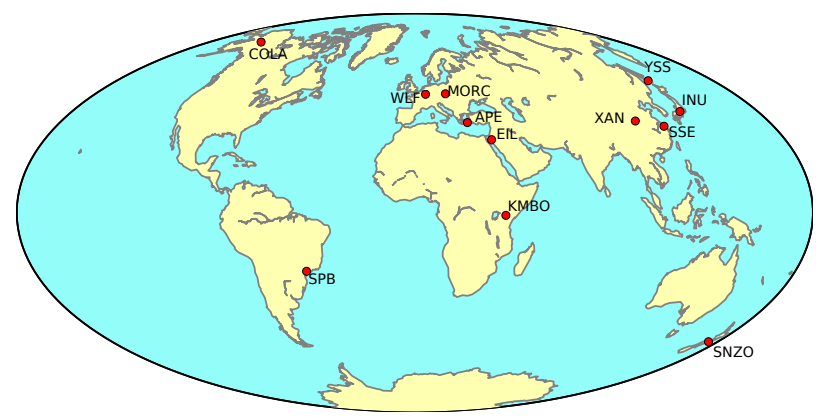

Figure 8: Comparison between observed and synthetic receiver function (RF) waveforms computed for different compositional gradients as predicted by mantle convection simulations (e.g., Ballmer et al. 2015). a) Compositional profiles and corresponding shear-wave velocity $\left(\mathrm{V}_{\mathrm{s}}\right)$ structures. b) Synthetic RF waveforms for each proposed model. c) Observed RF waveforms. d) Geographic location of stationæqonsidered in panel c. 
tive plate boundaries (e.g., western US or northeast Eurasia), in oceanic regions (e.g., Hawaii and Iceland), and regions of intra-plate volcanism (e.g., Afar) that cannot be explained by a compositionally uniform and adabatic mantle. Figure 8 depicts synthetic RF waveforms computed for different depth-dependent compositional profiles based on predictions from mantle convection simulations (e.g., Tackley, 2008; Ballmer et al., 2015). We find an overall agreement between the observed and synthetic waveforms between 60 and 75 seconds (P660s) suggesting that a significant part of the complexity present in the RF waveform data between 60 and 75 seconds (P660s) can be explained by local radial changes in mantle composition. Variations in P660s travel time present in the observed RF waveforms (Figure 8p) most likely reflect local changes in upper mantle velocities due to thermal and compositional variations. Despite being a qualitative comparison, this result supports the existence of local lower-mantle enrichment in basalt ( $\sim 5-10 \%$ with respect to the upper mantle) and the local accumulation of basalt $(\sim 15-30 \%)$ in the MTZ. A detailed characterization of these radial changes would require the use of more advanced wave propagation techniques (Monteiller et al. 2012) that account for effects introduced by complex three-dimensional structure. Compositional layering has also been found necessary to explain regional SS precursors signals beneath Hawaii (Yu et al., 2018) and narrow high-velocity anomalies beneath the MTZ in regions of mantle upwellings (Maguire et al. 2017). Although the detailed morphology of mantle compositional gradients remains uncertain, all these observations support geodynamical simulations that describe mantle convection as a mixture of layered and whole-mantle convection (Tackley, 2000), where cold and/or basaltic material accumulates above $660 \mathrm{~km}$ depth until huge avalanches precipitate it into the lower mantle, "flushing" the local upper mantle through broad cylindrical downwellings to the core-mantle boundary in a globally asynchronous manner (e.g., Tackley, 2008). 


\section{Conclusions}

In this paper, we investigated whether compositional mantle stratification is required to jointly explain short- (P-to-s receiver functions) and long-period (Rayleigh wave dispersion) seismic data sensitive to upper mantle and transition zone structure beneath a number of different tectonic settings. This is achieved by implementing a methodology that interfaces the geophysical inversion with self-consistent calculations of mineral phase equilibria on a new global highquality dataset of receiver function waveforms from an initial pool of 155 stations enhanced with the most recent available global dataset of Rayleigh wave phase velocity dispersion for the fundamental mode and up to fifth overtone.

We showed that a compositional boundary is not required to explain shortand long-period seismic data sensitive to the upper mantle and transition zone beneath stable continental regions; yet, radial enrichment in basaltic material reproduces part of the complexity present in the data recorded near subduction zones and volcanically active regions. Our findings further suggest that the mantle is neither completely chemically equilibrated nor fully mechanically mixed, but appears to be best described as an in-between amalgam. In particular, chemical equilibration seems less prevalent beneath cratons suggesting that these regions are possibly isolated from convection processes.

Future work will focus on further investigation of the morphology of mantle compositional gradients near subduction zones and volcanically active regions. This will require the incorporation of: 1) a depth-dependent composition and deviations from adiabatic profiles; 2) wave propagation simulations based on more advanced waveform modeling (e.g., Monteiller et al., 2012) to account for three-dimensional effects; and 3) additional information from other geophysical

†echniques such as Love phase and group velocities (e.g., Khan et al., 2009, Calò et al. 2016) or S-to-p converted waves (Oreshin et al., 2008, Yuan et al., 2006) to improve the resolution in the upper mantle. 


\section{Acknowledgments}

We are grateful to John Brodholt and an anonymous reviewer for comments that led to an improved manuscript. This work was supported by the Swiss National Science Foundation (SNSF project 159907). B.T. was funded by the European Union's Horizon 2020 research and innovation program under the Marie Sklodowska-Curie grant agreement 793824. Calculations were performed using the ETH Zurich cluster Euler.

\section{References}

Anderson, D.L., 2007. New theory of the Earth. Cambridge University Press.

Bagheri, A., Khan, A., Al-Attar, D., Crawford, O., Giardini, D., 2019. Tidal response of Mars constrained from laboratory-based viscoelastic dissipation models and geophysical data. Journal of Geophysical Research: Planets doi:10.1029/2019JE006015.

Ballard, S., Pollack, H.N., 1987. Diversion of heat by Archean cratons: a model for southern Africa. Earth and Planetary Science Letters 85, 253-264.

Ballmer, M.D., Schmerr, N.C., Nakagawa, T., Ritsema, J., 2015. Compositional mantle layering revealed by slab stagnation at $\sim 1000-\mathrm{km}$ depth. Science advances 1, e1500815.

Bernstein, S., Kelemen, P.B., Brooks, C.K., 1998. Depleted spinel harzburgite xenoliths in Tertiary dykes from East Greenland: restites from high degree melting. Earth and Planetary Science Letters 154, 221-235.

Boyd, F., Pokhilenko, N., Pearson, D., Mertzman, S., Sobolev, N., Finger, L., 1997. Composition of the Siberian cratonic mantle: evidence from Udachnaya peridotite xenoliths. Contributions to Mineralogy and Petrology 128, 228-246.

Calò, M., Bodin, T., Romanowicz, B., 2016. Layered structure in the upper mantle across North America from joint inversion of long and short period seismic data. Earth and Planetary Science Letters 449, 164-175. 
Carlson, R.W., Pearson, D.G., James, D.E., 2005. Physical, chemical, and chronological characteristics of continental mantle. Reviews of Geophysics 43.

Cline II, C., Faul, U., David, E., Berry, A., Jackson, I., 2018. Redox-influenced seismic properties of upper-mantle olivine. Nature 555, 355.

Cobden, L., Goes, S., Cammarano, F., Connolly, J.A., 2008. Thermochemical interpretation of one-dimensional seismic reference models for the upper mantle: evidence for bias due to heterogeneity. Geophysical Journal International $175,627-648$

Connolly, J., 2009. The geodynamic equation of state: what and how. Geochemistry, Geophysics, Geosystems 10.

Connolly, J., Khan, A., 2016. Uncertainty of mantle geophysical properties computed from phase equilibrium models. Geophysical Research Letters 43, $5026-5034$.

Cottaar, S., Deuss, A., 2016. Large-scale mantle discontinuity topography beneath Europe: Signature of akimotoite in subducting slabs. Journal of Geophysical Research: Solid Earth 121, 279-292.

Deuss, A., Andrews, J., Day, E., 2013. Seismic observations of mantle discontinuities and their mineralogical and dynamical interpretation. Physics and Chemistry of the Deep Earth , 297-323.

Deuss, A., Redfern, S.A., Chambers, K., Woodhouse, J.H., 2006. The nature of the 660-kilometer discontinuity in Earth's mantle from global seismic observations of PP precursors. Science 311, 198-201.

Durand, S., Debayle, E., Ricard, Y., 2015. Rayleigh wave phase velocity and error maps up to the fifth overtone. Geophysical Research Letters 42, 32663272. 
Efron, B., Tibshirani, R., 1991. Statistical data analysis in the computer age. Science, 390-395.

French, S., Romanowicz, B., 2014. Whole-mantle radially anisotropic shear velocity structure from spectral-element waveform tomography. Geophysical Journal International 199, 1303-1327.

Frost, D.J., Dolejš, D., 2007. Experimental determination of the effect of $\mathrm{H}_{2} \mathrm{O}$ on the $410-\mathrm{km}$ seismic discontinuity. Earth and Planetary Science Letters 256, 182-195.

Ghosh, S., Ohtani, E., Litasov, K.D., Suzuki, A., Dobson, D., Funakoshi, K., 2013. Effect of water in depleted mantle on post-spinel transition and implication for $660 \mathrm{~km}$ seismic discontinuity. Earth and Planetary Science Letters $371,103-111$.

Hansen, N., Ros, R., Mauny, N., Schoenauer, M., Auger, A., 2011. Impacts of invariance in search: When CMA-ES and PSO face ill-conditioned and non-separable problems. Applied Soft Computing 11, 5755-5769.

Helffrich, G., 2000. Topography of the transition zone seismic discontinuities. Reviews of Geophysics 38, 141-158.

Herzberg, C., Asimow, P.D., Arndt, N., Niu, Y., Lesher, C., Fitton, J., Cheadle, M., Saunders, A., 2007. Temperatures in ambient mantle and plumes: Constraints from basalts, picrites, and komatiites. Geochemistry, Geophysics, Geosystems 8.

Hofmann, A., Hart, S., 1978. An assessment of local and regional isotopic equilibrium in the mantle. Earth and Planetary Science Letters 38, 44-62.

Ita, J., Stixrude, L., 1992. Petrology, elasticity, and composition of the mantle transition zone. Journal of Geophysical Research: Solid Earth 97, 6849-6866.

Jain, C., Rozel, A., Tackley, P., 2019. Quantifying the correlation between mobile continents and elevated temperatures in the subcontinental mantle. Geochemistry, Geophysics, Geosystems 20, 1358-1386. 
Jordan, T.H., 1978. Composition and development of the continental tectosphere. Nature 274, 544 .

Katsura, T., Yoneda, A., Yamazaki, D., Yoshino, T., Ito, E., 2010. Adiabatic temperature profile in the mantle. Physics of the Earth and Planetary Interiors $183,212-218$.

Khan, A., Boschi, L., Connolly, J., 2009. On mantle chemical and thermal heterogeneities and anisotropy as mapped by inversion of global surface wave data. Journal of Geophysical Research: Solid Earth 114.

Khan, A., Connolly, J., Taylor, S., 2008. Inversion of seismic and geodetic data for the major element chemistry and temperature of the Earth's mantle. Journal of Geophysical Research: Solid Earth 113.

Kopylova, M.G., Russell, J.K., 2000. Chemical stratification of cratonic lithosphere: constraints from the Northern Slave craton, Canada. Earth and Planetary Science Letters 181, 71-87.

Lawrence, J.F., Shearer, P.M., 2006a. Constraining seismic velocity and density for the mantle transition zone with reflected and transmitted waveforms. Geochemistry, Geophysics, Geosystems 7.

Lawrence, J.F., Shearer, P.M., 2006b. A global study of transition zone thickness using receiver functions. Journal of Geophysical Research: Solid Earth 111.

Lenardic, A., Moresi, L., Jellinek, A., O’neill, C., Cooper, C., Lee, C., 2011. Continents, supercontinents, mantle thermal mixing, and mantle thermal isolation: Theory, numerical simulations, and laboratory experiments. Geochemistry, Geophysics, Geosystems 12.

Lenardic, A., Moresi, L.N., Jellinek, A., Manga, M., 2005. Continental insulation, mantle cooling, and the surface area of oceans and continents. Earth and Planetary Science Letters 234, 317-333. 
Ligorria, J.P., Ammon, C.J., 1999. Iterative deconvolution and receiver-function estimation. Bulletin of the seismological Society of America 89, 1395-1400.

Maguire, R., Ritsema, J., Goes, S., 2017. Signals of $660 \mathrm{~km}$ topography and harzburgite enrichment in seismic images of whole-mantle upwellings. Geophysical Research Letters 44, 3600-3607.

Mattern, E., Matas, J., Ricard, Y., Bass, J., 2005. Lower mantle composition and temperature from mineral physics and thermodynamic modelling. Geophysical Journal International 160, 973-990.

McKenzie, D., Bickle, M., 1988. The volume and composition of melt generated by extension of the lithosphere. Journal of petrology 29, 625-679.

Monteiller, V., Chevrot, S., Komatitsch, D., Fuji, N., 2012. A hybrid method to compute short-period synthetic seismograms of teleseismic body waves in a 3-D regional model. Geophysical Journal International 192, 230-247.

Mosegaard, K., Tarantola, A., 1995. Monte Carlo sampling of solutions to inverse problems. Journal of Geophysical Research: Solid Earth 100, 1243112447 .

Muller, G., 1985. The reflectivity method - A tutorial. Journal of GeophysicsZeitschrift Fur Geophysik 58, 153-174.

Munch, F.D., Khan, A., Tauzin, B., Zunino, A., Giardini, D., 2018. Stochastic inversion of P-to-s converted waves for mantle composition and thermal structure: Methodology and application. Journal of Geophysical Research: Solid Earth .

Murakami, M., Ohishi, Y., Hirao, N., Hirose, K., 2012. A perovskitic lower mantle inferred from high-pressure, high-temperature sound velocity data. Nature 485, 90.

Nakagawa, T., Buffett, B.A., 2005. Mass transport mechanism between the upper and lower mantle in numerical simulations of thermochemical mantle 
convection with multicomponent phase changes. Earth and Planetary Science Letters 230, 11-27.

Oreshin, S., Kiselev, S., Vinnik, L., Prakasam, K.S., Rai, S.S., Makeyeva, L., Savvin, Y., 2008. Crust and mantle beneath western Himalaya, Ladakh and western Tibet from integrated seismic data. Earth and Planetary Science Letters $271,75-87$.

Pearson, D., Canil, D., Shirey, S., 2003. Mantle samples included in volcanic rocks: xenoliths and diamonds. Treatise on geochemistry 2, 568 .

Ringwood, A., 1975. Composition and petrology of the Earth's mantle.

Ritsema, J., Xu, W., Stixrude, L., Lithgow-Bertelloni, C., 2009. Estimates of the transition zone temperature in a mechanically mixed upper mantle. Earth and Planetary Science Letters 277, 244-252.

Rolf, T., Coltice, N., Tackley, P., 2012. Linking continental drift, plate tectonics and the thermal state of the Earth's mantle. Earth and Planetary Science Letters $351,134-146$.

Schaeffer, A., Lebedev, S., 2013. Global shear speed structure of the upper mantle and transition zone. Geophysical Journal International 194, 417-449.

Schaeffer, A., Lebedev, S., 2015. Global heterogeneity of the lithosphere and underlying mantle: A seismological appraisal based on multimode surface-wave dispersion analysis, shear-velocity tomography, and tectonic regionalization, in: The Earth's heterogeneous mantle. Springer, pp. 3-46.

Schmandt, B., 2012. Mantle transition zone shear velocity gradients beneath USArray. Earth and Planetary Science Letters 355, 119-130.

Schulze, K., Marquardt, H., Kawazoe, T., Ballaran, T.B., McCammon, C., Koch-Müller, M., Kurnosov, A., Marquardt, K., 2018. Seismically invisible water in Eearth's transition zone? Earth and Planetary Science Letters 498, $9-16$. 
Sobolev, A.V., Hofmann, A.W., Kuzmin, D.V., Yaxley, G.M., Arndt, N.T., Chung, S.L., Danyushevsky, L.V., Elliott, T., Frey, F.A., Garcia, M.O., et al., 2007. The amount of recycled crust in sources of mantle-derived melts. Science $316,412-417$.

Stixrude, L., Lithgow-Bertelloni, C., 2011. Thermodynamics of mantle mineralsII. Phase equilibria. Geophysical Journal International 184, 1180-1213.

Tackley, P.J., 2000. Self consistent generation of tectonic plates in timedependent, three dimensional mantle convection simulations, part 1: Pseudoplastic yielding. G3 1 .

Tackley, P.J., 2008. Geodynamics: Layer cake or plum pudding? Nature Geoscience 1, 157.

Tauzin, B., Debayle, E., Wittlinger, G., 2008. The mantle transition zone as seen by global Pds phases: no clear evidence for a thin transition zone beneath hotspots. Journal of Geophysical Research: Solid Earth 113.

Thio, V., Cobden, L., Trampert, J., 2015. Seismic signature of a hydrous mantle transition zone. Physics of the Earth and Planetary Interiors 250, 46-63.

Wang, F., Barklage, M., Lou, X., van der Lee, S., Bina, C.R., Jacobsen, S.D., 2018. HyMaTZ: a Python program for modeling seismic velocities in hydrous regions of the mantle transition zone. Geochemistry, Geophysics, Geosystems 19, 2308-2324.

Wu, W., Ni, S., Irving, J.C., 2019. Inferring Earth's discontinuous chemical layering from the 660-kilometer boundary topography. Science 363, 736-740.

Xu, W., Lithgow-Bertelloni, C., Stixrude, L., Ritsema, J., 2008. The effect of bulk composition and temperature on mantle seismic structure. Earth and Planetary Science Letters 275, 70-79.

Yu, C., Day, E.A., Maarten, V., Campillo, M., Goes, S., Blythe, R.A., van der Hilst, R.D., 2018. Compositional heterogeneity near the base of the mantle transition zone beneath Hawaii. Nature Communications 9, 1266. 
${ }_{611}$ Yuan, X., Kind, R., Li, X., Wang, R., 2006. The S receiver functions: synthetics and data example. Geophysical Journal International 165, 555-564. 

Supplementary material for online publication only
Click here to download Supplementary material for

Click here to download Supplementary material for online publication only: Munch_et_al_SM.pdf tor

(1)

$\sqrt{3}$ (1)

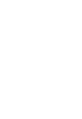

